\title{
Thermal and Mechanical Properties of Sol-Gel Silica Coated Fabrics
}

\author{
Abdullah Tav ${ }^{1}$, Yahya Öz ${ }^{2}$, Halil İ. Akyıldız ${ }^{3 *}$ \\ ${ }^{1}$ Bursa Uludag University, Graduate School of Natural and Applied Science, Departmant of Polymeric Materials, Bursa, Turkey, \\ (ORCID: 0000-0002-6999-8548), abdullahtav@uludag.edu.tr \\ 2 Turkish Aerospace, R\&D Directorate, Advanced Materials, Processes and Energies Technology Center, Ankara, Turkey, \\ (ORCID: 0000-0003-3784-0495), yahya.oz@ tai.com.tr \\ 3* Bursa Uludag University, Faculty of Engineering, Departmant of Textile Engineering, Bursa, Turkey, \\ (ORCID: 0000-0002-8727-5829), halilakyildiz@uludag.edu.tr
}

(First received 25 September 2021 and in final form 23 December 2021)

(DOI: 10.31590/ejosat.1000774)

ATIF/REFERENCE: Tav, A., Öz, Y. \& Akyıldız, H. İ. (2021). Thermal and Mechanical Properties of Sol-Gel Silica Coated Fabrics. European Journal of Science and Technology, (31), 309-319.

\begin{abstract}
Sol-gel method is a versatile materials synthesis method via which numerous materials can be produced in various forms. The method also can be utilized for the modification of materials surfaces. Textile substrates being relatively inexpensive and flexible, can be used in composite structures for high technology applications. In this study, silica sol suspensions prepared via hydrolysis of tetraethyl orthosilicate were used to coat cotton, polyamide 6.6 (PA 6.6), and polyethylene terephthalate (PET) fabrics and to alter their thermal and mechanical properties. The coating process was conducted by applying the silica sol suspension to the fabric without any other additive and with poly(vinyl alcohol) (PVA) employed as a binder. The morphologies of the materials before and after the coating process were analyzed with SEM, and uniform coating of the fabrics was confirmed. FTIR spectra of the samples were compared to observe changes in the chemical functional groups, which showed the decrease in the substrate polymer peaks upon coating and the presence of Si-O bonding in some instances. The silica coating effect on the fabric samples' thermal degradation was investigated using thermogravimetric analysis (TGA), showing that the thermal degradation behavior of the polymers mainly remained the same after the coating process. However, amounts of residual materials after burnout have differed with the coating type. The coatings' mechanical performances were tested with tensile testing, which showed that the effect of the coating is highly dependent on the fabric material.
\end{abstract}

Keywords: Sol-gel, Silica, Coating, Cotton, Polyamide 6.6, Polyethylene terephthalate.

\section{Sol-Jel Silika Kaplanmış Kumaşların Isıl ve Mekanik Özellikleri}

$\ddot{O} z$

Sol-jel yöntemi çok çeşitli malzemelerin üretilebildiği, çok kullanışlı bir malzeme sentez yöntemidir. Bu yöntem, malzeme yüzeylerinin modifikasyonu içinde kullanılabilmektedir. Görece ucuz ve esnek yapıda olan tekstil malzemeleri, yüksek teknoloji kompozit uygulamaları için de kullanılmaktadır. Bu çalışmada, tetraetil ortosilikatın hidrolizi ile hazırlanan silika sol süspansiyonları, pamuk, poliamid 6.6 (PA 6.6) ve polietilen tereftalat (PET) kumaşlarını kaplamak için kullanılmış olup termal ve mekanik özelliklerine olan etkisi incelenmektedir. Silika sol süspansiyonu içerisine herhangi ilave bir katkı kullanılmadan ve bağlayıcı olarak poli(vinil alkol) (PVA) kullanılarak kumaşların kaplaması gerçekleştirilmiştir. Malzemelerin morfolojileri kaplama işleminden önce ve sonra SEM ile analiz edilmiş olup kaplamaların kumaş yüzeylerinde düzgün dağıldığı teyit edilmiştir. Fonksiyonel gruplardaki değişiklikleri gözlemlemek için numunelerin FTIR spektrumu ile kaplanmış malzemelerin kimyasal yapıları karşılaştırılmıştır. Numunelerin FTIR spektrumları kaplama sonrasında polimer piklerinin kaplama sonrası azaldığını ve bazı numunelerde Si-O bağlanma durumlarını göstermiştir. Silika kaplanmış kumaş numunelerinin termal bozunması üzerindeki etkisi, termogravimetrik analiz (TGA) kullanılarak incelenmektedir. Kaplama sonrasında polimerlerin ısıl bozunma davranışlarının büyük ölçüde aynı kaldığı ancak kalıntı miktarlarında kaplama türüne göre farklılıklar gösterdiği gözlemlenmiştir. Kaplamaların mekanik performansı, büyük ölçüde kumaş malzemesine bağlı olduğu, çekme testi ile tespit edilmiştir. Çekme testleri sonucu kaplamalı kumaşların mekanik performansının büyük ölçüde kumaş hammaddesine bağlı olduğunu göstermiştir.

Anahtar Kelimeler: Sol-jel, Silika, Kaplama, Pamuk, Poliamid 6.6, Polietilen tereftalat. 


\section{Introduction}

There is an increasing interest in the modification of textile fabric surfaces for a wide variety of applications. Traditional and innovative methods have been utilized to improve the surface properties of natural and synthetic textile fabrics to expand textile materials' applications via the acquisition of unique properties (Ghasemi, Mirzadeh, Bates, \& Kamal, 2014; Periyasamy, Venkataraman, Kremenakova, Militky, \& Zhou, 2020). Products of surface modification are of interest for membranes (Prevolnik, Zrim, \& Rijavec, 2014), water resistivity (Purwar, Sharma, Sahoo, \& Srivastava, 2015), wear resistance (Shahidi \& Wiener, 2013), various composites (De Campos et al., 2014), optical applications (Akyildiz et al., 2014) and biomaterials (Amann \& Minge, 2012). The modification methods can be roughly classified into chemical (wet) and mechanical (dry) modifications. Among these surface modification methods, application of nanoparticles (Akyildiz, Stano, Roberts, Everitt, \& Jur, 2016), plasma treatment (Nadi, Boukhriss, Bentis, Jabrane, \& Gmouh, 2018), nanoparticles, chemical vapor deposition (Akyildiz et al. 2014), and sol-gel methods (Teli \& Annaldewar, 2017) are commonly used as chemical methods.

The sol-gel method is a material formation technique utilizing wet chemistry, which can be applied for surface functionalization. During a sol-gel process, the advancement of an inorganic colloidal suspension ( $\mathrm{sol}$ ) and gelation of the sol to a persistent fluid form (gel) creates a moldable material. Along with the cost-saving and straightforward processability, the solgel method also provides essential advantages such as high purity, low process temperature, and a wide selection of starting monomers for a promising route to diverse compositions of materials. Especially in the last 20 years, advanced functional applications for high added value enabled growing interest in this technique (X. Xu, Li, Lu, Zhang, \& Wang, 2007). Silica solgel reactions are heavily studied in the literature. Usual silica precursor sources for the silanization are silicon alkoxides such as TEOS (tetraethyl orthosilicate) and TMOS (tetramethyl orthosilicate). The TEOS precursor is easy to process and less toxic than TMOS, making it a more common precursor of choice (Ismail, 2016; Shahidi \& Wiener, 2013). After silica gel is produced, it can create different forms of materials such as fibers (Pirzada, Arvidson, Saquing, Shah, \& Khan, 2012), films (Gurav, Jung, Park, Kang, \& Nadargi, 2010), aerogel (Jelle, Baetens, \& Gustavsen, 2015; Pirzada et al., 2012; J. W. Wu, Huang, Li, Runt, \& Yeh, 2018), or bulk materials (Pisal \& Rao, 2016).

Furthermore, silica materials made with different precursors can also be integrated into textile materials for various applications, mainly focusing on modifying the surface properties (Islam, Yu, \& Naveed, 2019; Talebi, Habibi, \& Zadhoush, 2018). Polysiloxanes, alkylsilanes, or their nanoparticles are covalently or physically bonded to cotton substrates tested for superhydrophobic applications with lower surface tension and higher surface roughness (Berendjchi, Khajavi, \& Yazdanshenas, 2013; Roe \& Zhang, 2009). Xu et al. tried $\mathrm{SiO}_{2}$ and $\mathrm{ZnO}$ nanoparticles and achieved superhydrophobic surfaces with increased toughness due to tremendous hydroxyl groups on the nanoparticles (Boticas et al., 2019).

One of the great challenges of integrating inorganic species to polymeric textiles is the low adhesion due to the lack of strong chemical interaction between the materials (Lee, Choe, Kim, Lee, \& Hwang, 2018). This challenge results in mechanical mismatch and limits the application of sol-gel coated materials. Due to the lack of silica's secondary bonding sites, adhesion on many substrates is not strong enough. Using binding polymers such as poly(vinyl alcohol) (PVA), poly(vinyl pyrrolidone) (PVP) can help to overcome these barriers and improve mechanical properties. For this purpose, film-forming materials with hydroxyl functional groups, like poly(vinyl alcohol) (PVA), were utilized as a binder in the literature (Nampi et al., 2011). Mehrdad Kokabiet al. prepared the PVA/clay wound dressings (Kokabi, Sirousazar, \& Hassan, 2007), Jiangtao Xu et al. deposited Ag nanoparticles using the PVA padding method on cotton fabric (J. Xu et al., 2019), Natarajan et al. using PVA to surface modification polyester fabric to comfort properties changing hydrophilic character (Natarajan \& Jeyakodi Moses, 2012). PVA is soluble in water and can interact with silica materials making it a better candidate to integrate silica materials into textile substrates. While mediating chemical interactions with silica coatings, it also acts as a flexible medium for them (Pingan, Mengjun, Yanyan, \& Ling, 2017). Pingan et al. showed this effect by creating freestanding silica-PVA composite materials and testing their mechanical properties (Pingan et al., 2017).

In this study, cotton, polyamide 6.6 (PA 6.6), and polyethylene terephthalate (PET) fabric substrates were coated with silica to improve the thermal and mechanical properties. Silica coating was conducted via dip coating of the fabrics into silica sol, prepared with TEOS precursor with and without the PVA binder's presence. Polymeric textile materials were chosen since they have different functional groups (i.e., cotton-OH, PA $6.6-\mathrm{NH}$, and PES - COO), expecting that they will interact with the coating solutions in different ways. The motivation for this research is two-fold. On the one hand, modifying properties like the mechanical and thermal behavior of fabrics used in different engineering applications like structural parts of aerospace platforms is of great interest for researchers and engineers since typically different requirements are formulated for distinct parts. This study proves that with varying coating materials, different properties of fabrics can be achieved. On the other hand, this study is a first step for paving the way for obtaining coated fabrics with multifunctional properties for advanced engineering applications like heat blankets in helicopters. With wholesome approach effects of each component in the coating solution were investigated on different substrates. Samples were characterized using SEM, FTIR, TGA, and tensile testing to understand each coating's structure and performance relationship.

\section{Material and Method}

\subsection{Materials}

Tetraethyl orthosilicate (TEOS, 98\%, CAS\# 78-10-4) and poly (vinyl alcohol) $(\mathrm{PVA}=88000 \mathrm{Da}$, acetylation between 87.0 89.0\%, CAS\# 9002-89-5) was purchased from Sigma Aldrich. Hydrochloric acid ( $\mathrm{HCl} 37 \%$ aqueous solution) and absolute ethanol (EtOH, $99.9 \%$ ) were purchased from Isolab Chemicals. Deionized water (DI) was used throughout the experiments. All chemicals were used as received without further processing. Cotton (plain weave), PA 6.6 (twill weave), and PET fabric (twill weave) were made of $100 \%$ of the same material and used without further processing. Fabrics were conditioned by keeping 
samples for 24 hours in a room at $25{ }^{\circ} \mathrm{C}$ and $65 \%$ relative humidity.

\subsection{Methods}

Silica sol was prepared via TEOS hydrolysis in EtOH and water with a weight ratio of $3: 2: 1$, respectively. The hydrolysis is initiated under acidic conditions by the dropwise addition of $0.005 \mathrm{M} \mathrm{HCl}$ to adjust $\mathrm{pH}$ 2. The hydrolysis was carried out for 1 hour at room temperature at $\mathrm{pH}$ 2. PVA solution was prepared in DI water with 5 wt.\% concentration in three steps. The desired amount of PVA was ensured to soak and swell in the water before stirring. This way, a more straightforward dissolution process was provided without dissolving the polymer chains. Then the mixture was processed with an ultrasonic bath at $60{ }^{\circ} \mathrm{C}$ for 2 hours. The dissolving process was finished with magnetic stirring at $90{ }^{\circ} \mathrm{C}$ for 30 minutes to obtain a clear solution. Samples were dip-coated using silica sol, PVA solution, and Silica+PVA (1:1 volume ratio) solutions. Before coating, pristine specimens were conditioned for 24 hours in a climatically controlled room to achieve controlled moisture content in each of them. Then, specimens were dipped into each solution vertically. After sufficient submerging, specimens were taken out of the solution and suspended in the air until the dripping of excess solution stopped. Then they were placed into an oven to dry and cure at $80^{\circ} \mathrm{C}$ for 30 minutes. The same procedure was applied to each type of coating solution.

The samples were coated with an $\mathrm{Au} / \mathrm{Pd}$ thin film before surface morphologies were investigated in SEM. The corresponding micrographs were recorded using an FEI Quanta 200 FEG SEM operating under a high vacuum at $5 \mathrm{kV}$ potential while recording with a secondary electron detector. Fourier transform infrared (FTIR) spectra of these pristine and coated fabric substrates were recorded with a diamond crystal ATR attachment, using a Perkin Elmer Spectrum Two spectrometer in the wavenumber range from 400 to $4000 \mathrm{~cm}^{-1}$. The thermal stability of samples was determined via thermogravimetric analysis (TGA) from ambient temperature to $900{ }^{\circ} \mathrm{C}$ with a heating rate of $10{ }^{\circ} \mathrm{C} / \mathrm{min}$, using a TA Instrument TGA Q500 under a nitrogen atmosphere. The tensile tests of pristine and coated fabric substrates were carried out using a Shimadzu universal tensile test system according to the ISO 4606 standard in a climatically controlled room $\left(65 \% \mathrm{RH}, 25{ }^{\circ} \mathrm{C}\right)$. The specimens were measured for their elongation, stress, and strain up until breaking point. The test was performed with a Shimadzu universal testing system with a $5 \mathrm{kN}$ load cell.

\section{Results and Discussion}

Images of the fabric samples before and after coating with silica and PVA are given in Figure 1. The handle of the fabric samples showed changes after the coating process. When the fabrics were coated with silica sol, they became rigid and brittle. However, they remained flat like the original fabrics. Also, the only silica-coated samples were bent; dust particles were falling from the sample, indicating the rigidity of the coating. When the samples were coated with PVA, the handle of the fabrics slightly changed and became more rigid compared to the pristine samples. The coating also caused bending of the fabrics from the corners, attributed to fabrics being freestanding during the drying process; thus, PVA coating was shrinking during thermal drying. After samples were coated with silica and PVA mixture, they were more flexible than the only silica coated fabrics and more rigid than the PVA only coating. The presence of the PVA e-ISSN : 2148-2683 in the coating also reduced the dusting problem significantly. However, curving of the fabrics from edges also present for the silica+PVA coated samples.

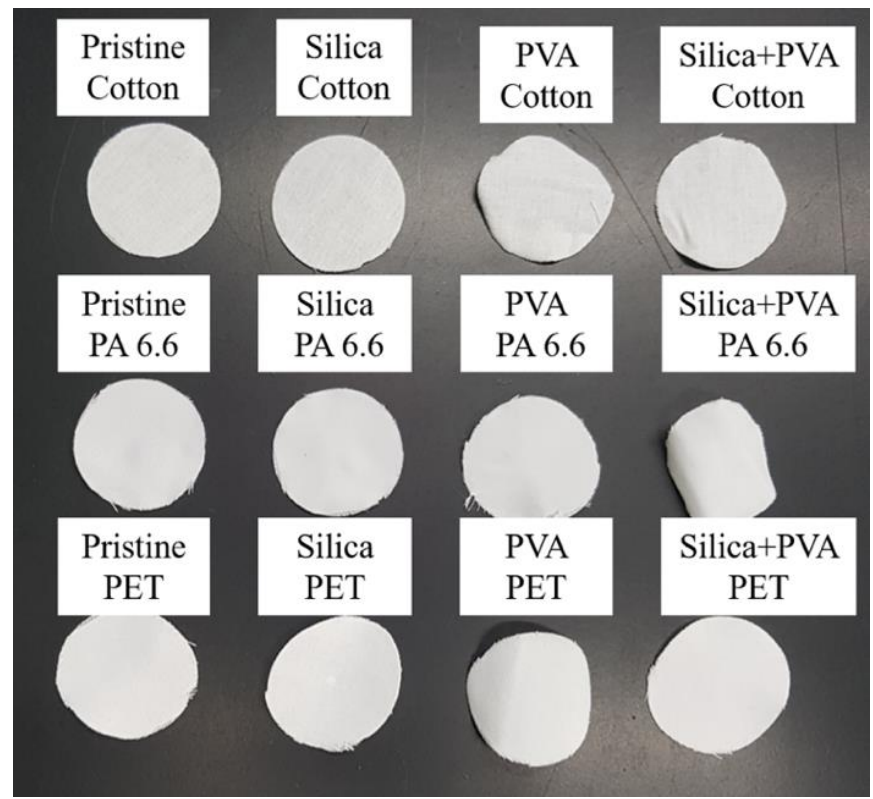

Figure 1: Images of cotton, PA 6.6, and PET fabrics with and without coatings.

SEM micrographs of the pristine and coated samples were obtained, and results are given in Figure 2 to observe the morphological changes on cotton fabrics upon the coating process. For the pristine cotton given in Fig. 2(a) plain weave structure of the fabric and the ribbon-like shape of the cotton fibers (inset image) are observable as expected. Surfaces of the pristine cotton fabrics are clean and free of any other materials. Upon dip coating of the cotton sample in silica sol, it goes through some changes as shown in Fig. 2(b). When the inset image is examined, fibers are coated independently of each other, indicating the sol could diffuse into the fabric well and be dispersed homogeneously throughout the fabric. The cotton sample coated in PVA solution is given in Fig. 2(c), which shows that polymer coating was also uniform on the sample surface. Compared to the cotton sample coated in silica sol, in PVA coated sample fibers are covered with the PVA and they are connected to each other via the coating. However, the yarns in the fabric are still independent of each other, and the fabric exhibits porosity. The coating gets thicker and more covering after coating the cotton fabric in the silica and PVA mixture, as seen in Fig. 2(d). The sample is covered with a film covering the whole surface of the fabric. It is clear that the coating is not as flexible as the fabric and has cracks forming due to the handling of the samples.

SEM image of the pristine PA 6.6 fabric is given in Fig. 3(a), showing the twill weave structure of the fabric made of multifilament fibers. Pristine PA 6.6 fabrics surface is clear and clean as expected. Upon PA 6.6 sample was dipped into a silica sol fabric surface covered with the silica material as shown in Fig. 3(b). Contrasting the cotton sample, upon silica coating of PA 6.6, the fabric's surface is covered more, and some of the pores between the yarns are filled with the coating. The inset image of Fig. 3(b) shows a coated region between two fibers and the brittle nature of the coating material. Sample coated in PVA solution, given in Fig. 3(c), shows similar morphology compared to changes to the cotton sample coated in PVA. When the fabric 
was coated in silica and PVA mixture, the fabric's surface is evenly coated, as seen in Fig. 3(d). The inlet image of the same sample clearly shows that PVA is acting as a binder that holds the fibers together. Furthermore, the PVA matrix is also expected to bind the silica particles to the fabric as it acts as a binder material.

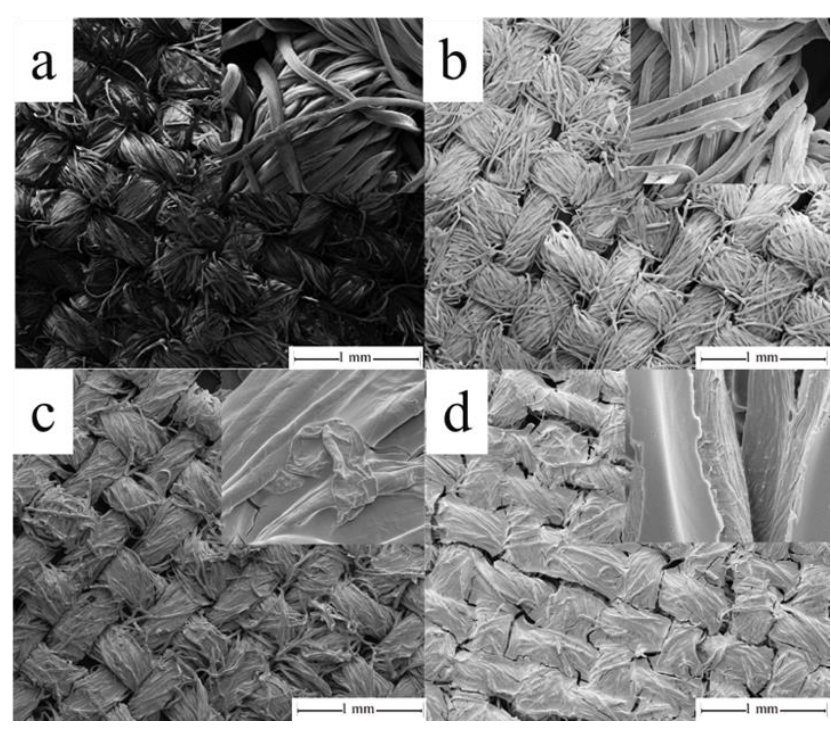

Figure 2: SEM micrographs of a) pristine, b) silica-coated, c) PVA coated, and d) silica $+P V A$ coated cotton fabrics.

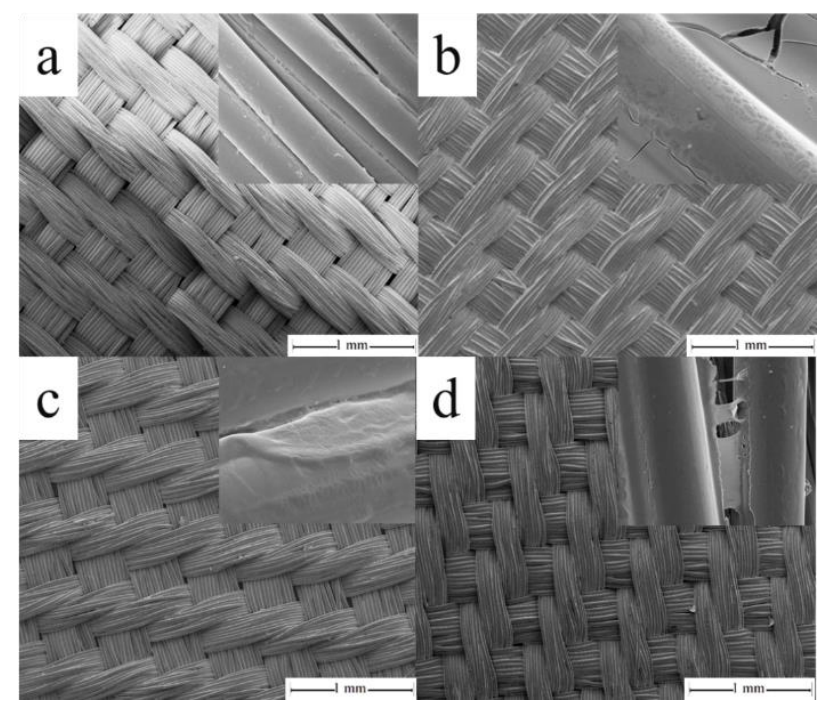

Figure 3: SEM micrographs of a) pristine, b) silica-coated, c) PVA coated, and d) silica+PVA coated PA 6.6 fabrics.

SEM micrograph of the pristine PET fabric is given in Fig. 4(a). The twill structure and smooth multifilament nature of the fabric are observable. The fabric structure still exists with the spaces between yarns upon silica coating, as seen in Fig. 4(b). As shown in the inset image, fiber surfaces are coated with silica, and the brittleness of the coating is visual. When the samples were coated in PVA solution, similar to other types of fabrics, the fabric is homogenously coated, the fiber to fiber bonding via PVA is evident, as shown in Fig. 4(c). Upon coating PET samples in silica and PVA mixture, Fig. 4(d) shows that the fibers are bound to each other, but yarns are not connected as much. Overall the silica coatings (Fig. 2(b), Fig. 3(b), Fig. 4(b)) on fabric samples show no agglomerates but complete smooth finishing. High magnification images of the silica-coated samples show the brittle nature of the silica coating. Furthermore, PVA acts as a binder to hold fibers together when applied to fabrics themselves. When applied with the silica sol, it also acts as a binder to hold the silica particles, explaining the less dusting of PVA+silica coated samples as discussed above. It can also be inferred that coating performance depends on the surface roughness and permeability characteristics of fabrics.

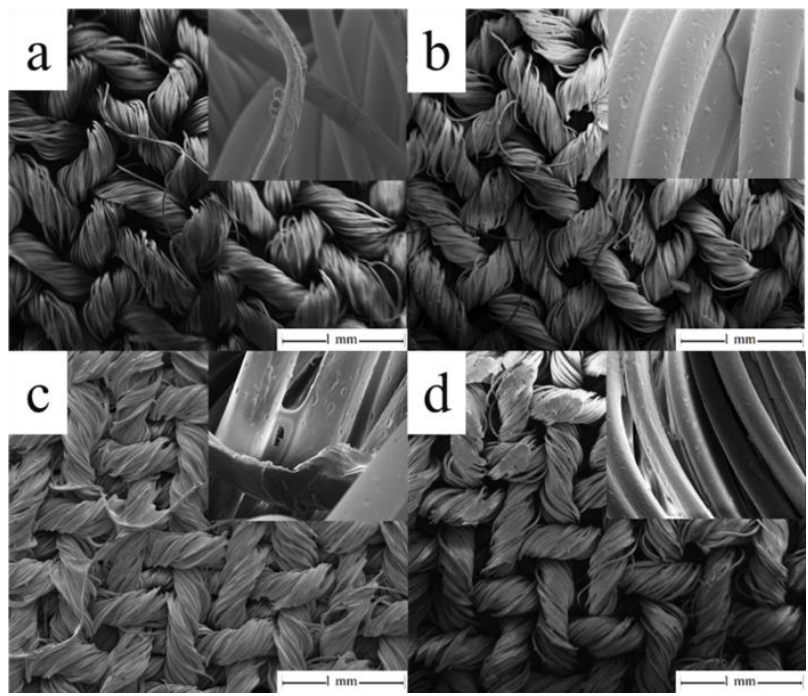

Figure 4: SEM micrographs of a) pristine, b) silica-coated, c) PVA coated, and d) silica+PVA coated PET fabrics.

FTIR spectra of pristine and coated fabrics were taken to investigate the changes in the samples' chemical functional groups. When the pristine cotton spectrum is analyzed in Figure 5 , the broad peak at $3300 \mathrm{~cm}^{-1}$ is attributed to the $-\mathrm{OH}$ stretching vibrations of cellulose. Signals at 1161, 1060, and $995 \mathrm{~cm}^{-1}$ are assigned to the $-(\mathrm{C}-\mathrm{O}-\mathrm{C})$ and $-(\mathrm{C}-\mathrm{O})$ stretching vibration of glucosidic units as suggested in the literature (Allen, Foulk, \& Gamble, 2007; Chung, Lee, \& Choe, 2004). However, upon coating the cotton fabric with colloidal silica sol, the pattern of the spectra of the silica-coated fabric does not show significant changes compared to the pristine fabric, except the intensity of the peaks coming from the polymer is decreased. According to the literature, the (Si-OH) stretch expected at $1081-995 \mathrm{~cm}^{-1}$ is eclipsed due to cotton's signals at the same region (Rosace, Guido, Colleoni, \& Barigozzi, 2016). Silica materials also have another peak expected to be observed at $791 \mathrm{~cm}^{-1}$ due to the ( $\mathrm{Si}-\mathrm{O}-\mathrm{Si}$ ) vibration shadowed by the cotton peaks at the same region. Therefore, the decrease in the intensity of cotton-related peaks is attributed to the presence of silica on the surface and can be accepted as evidence of silica coating (Zeng, Wang, Zhou, \& Lin, 2015). As a control, cotton fabric is also coated with only PVA to see any interaction between the substrate and the binder polymer. The spectrum of PVA-coated cotton is also given in Fig. 5. In the FTIR spectrum of pure PVA characteristic peaks of $-\mathrm{OH}$ groups, $\mathrm{CH}$ stretching and bending and $\mathrm{C}-\mathrm{O}$ stretch peaks are observed as given in the literature (Costa, Mansur, Pereira, \& Mansur, 2012; Mansur, Sadahira, Souza, \& Mansur, 2008). These peaks are also observed in the spectrum of the cotton. Due to the overlap of the functional groups, no significant change in the PVA-coated cotton spectrum is observed compared to the pristine fabric. Similarly, upon coating the fabric with PVA and silica, cotton peaks are observed to be dominant in all regions, blocking the observation of any peaks attributed to the presence of silica or PVA. However, the intensity of the spectrum is significantly higher than the only silica-coated sample indicating that with the addition of PVA, the amount of silica deposited on the surface is reduced $(\mathrm{G}$. $\mathrm{Wu}$ et al., 2020). 


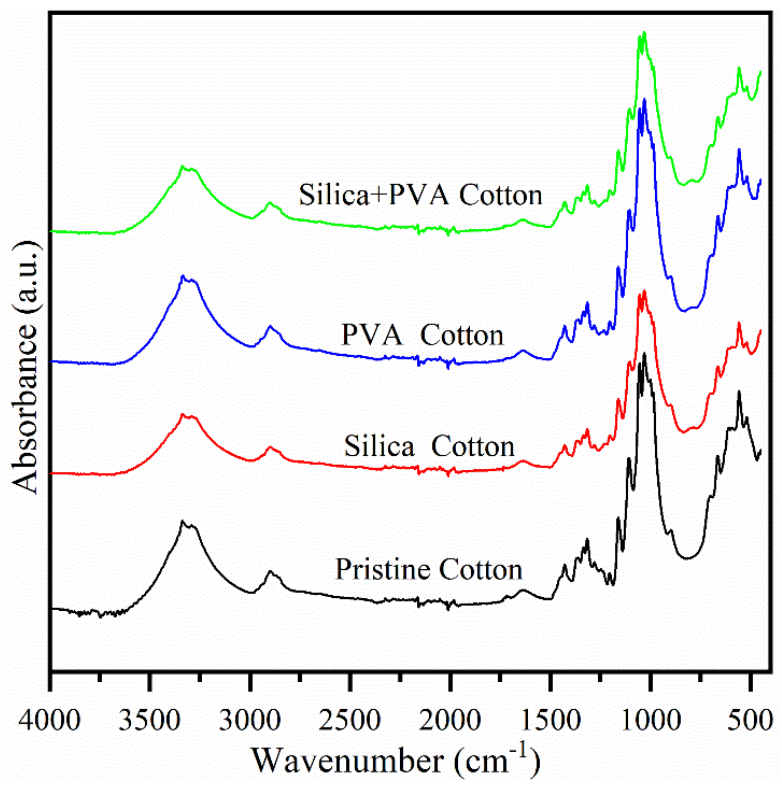

Figure 5: FTIR spectra of the pristine and coated cotton fabrics.

FTIR spectra of the pristine coated PA 6.6 samples are given in Figure 6. PA 6.6 chemical structure is made of aliphatic short $\mathrm{CH}_{2}$ chains connected with amide groups. Therefore, characteristic peaks of $\mathrm{CH}_{2}, \mathrm{~N}-\mathrm{H}$, and $\mathrm{C}=\mathrm{O}$ functional groups are expected in the spectrum. In the spectrum of pristine PA 6.6, N$\mathrm{H}$ group's stretching and bending signals are observed at 3295 and $1633 \mathrm{~cm}^{-1}$, respectively (F. Li, Xing, \& Ding, 2008; L. Li \& Yang, 2009) . Peaks observed at 2900 at $2800 \mathrm{~cm}^{-1}$ are attributed to the symmetric and asymmetric stretching of the $\mathrm{CH}_{2}$ groups in the polymer. Characteristic $\mathrm{C}=\mathrm{O}$ group peak of the PA 6.6 is observed at $1650 \mathrm{~cm}^{-1}$. Furthermore, the fingerprint region of the spectrum confirms the PA 6.6 structure of the pristine fabric samples. Upon silica sol coating of the PA 6.6 samples, the FTIR spectrum in Fig. 2(b) shows all these characteristic peaks of the PA 6.6 even if they were reduced in intensity. However, the intensity change is not the only change in the spectrum. The broad peak observed in the range of 3600 to $3300 \mathrm{~cm}^{-1}$ region, which is characteristic of $\mathrm{O}-\mathrm{H}$ groups, is increased in the intensity, which can be attributed to the presence of $\mathrm{Si}-\mathrm{OH}$ state of coated samples. Furthermore, two peaks observed at 1100 and $810 \mathrm{~cm}^{-1}$ also confirm the presence of the silica since they can be attributed to the -(Si-O-Si) stretching bands as suggested by the literature (Giustino, 2005; Rubio, Rubio, \& Oteo, 1998). Thus, during the coating process, we could deposit the silica material to the fabric surfaces. Once the sample is coated with the PVA, the FTIR spectrum again looks very similar to the pristine sample. In the chemical structure of the PVA, different than the $\mathrm{PA}$ 6.6, there are $\mathrm{O}-\mathrm{H}$ groups expected to have a broad peak presence in the spectrum. However, the observance of no significant change in the expected region (i.e., 3300-3600 $\mathrm{cm}^{-1}$ ) is attributed to the small amount of PVA deposition to the fabric surface, which is not necessarily a negative result nor unexpected. Nevertheless, a small amount of PVA would be preferable since PVA is considered a binder material rather than a coating material. After the PA 6.6 sample was coated with the PVA and silica together, the spectrum is very similar to the silica-coated PA 6.6 sample, indicating the silica material's successful deposition to the surface.

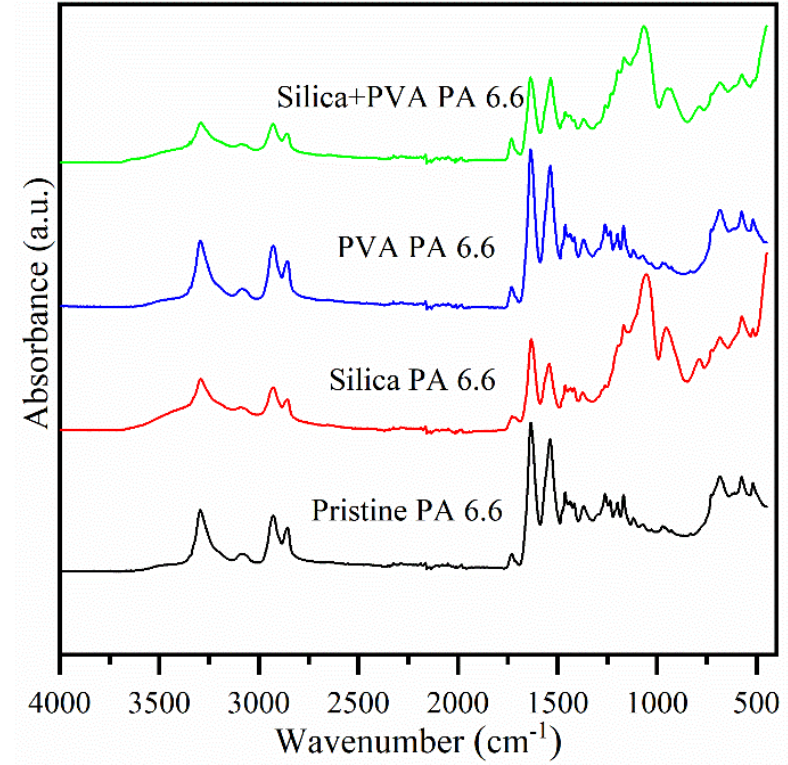

Figure 6: FTIR spectra of the pristine and coated PA 6.6 fabrics.

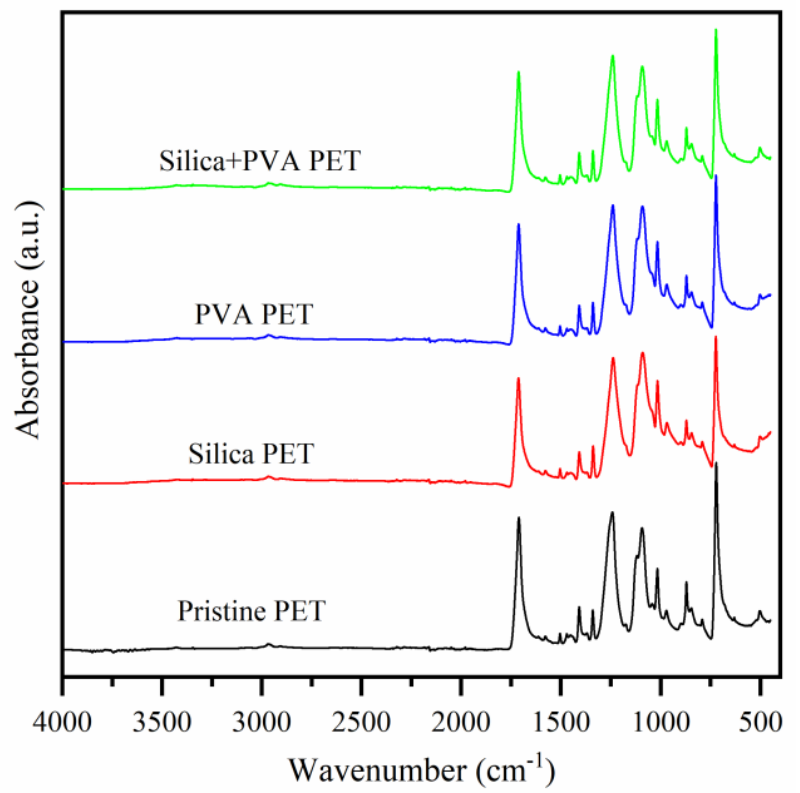

Figure 7: FTIR spectra of the pristine and coated PET fabrics.

FTIR spectra of the pristine and coated PET samples are given in Figure 7. In the pristine PET sample spectrum, the most notable vibration groups defining the PET are at 1720, 1096, and $1242 \mathrm{~cm}^{-1}$, associated with $-(\mathrm{C}=\mathrm{O})$ groups in the ester groups of the polymer. Additionally, a peak at $2912 \mathrm{~cm}^{-1}$ can be attributed to the symmetrical stretching of the $-(\mathrm{C}-\mathrm{H})$ group and the characteristic of PET. Upon coating PET with silica sol, peaks remain primarily similar to the pristine fabric, except a slight change observed in the range of 1100 to $800 \mathrm{~cm}^{-1}$. In this range, the spectrum's baseline is increased, which can be associated with new material. As mentioned above, Si-O vibrations are expected in this range. Thus this change can be attributed to the silica presence after the coating (Giustino, 2005). After the sample is coated with PVA, the spectrum is very similar to the pristine PET sample. As for the PA 6.6 sample, this result is attributed to the minimal uptake of the PVA onto the PET fabric. Sample coated with silica and PVA shows a spectrum with very minimal change compared to the pristine sample. When all the 
spectra are compared, the silica material's presence is more dominant in the PA 6.6 samples than the cotton and PET (Giustino, 2005; Rubio et al., 1998). This result might be an indication of more interaction taking place between the amide groups and silica sol species. Nonetheless, $\mathrm{OH}$ groups of the cotton and ester groups of the PET do not show the same interaction.

The thermal behavior of pristine and coated textile substrates surveyed by thermogravimetric analysis under the nitrogen environment is given in Figure 8. According to the TGA results of the cotton fabrics given in Fig. 8, the pristine cotton sample shows the first weight loss step that starts at $100{ }^{\circ} \mathrm{C}$ associated with the sample's water loss. Since cotton is a hygroscopic material, it can absorb water from a humid environment; thus, in this step, about $5 \%$ of the weight was lost. The second weight-loss step, which onsets at $280{ }^{\circ} \mathrm{C}$ and lasts until $400{ }^{\circ} \mathrm{C}$ is attributed to the decomposition of the polymer. At this stage, most of the polymer decomposed into volatile species as well as to a char. Above $400{ }^{\circ} \mathrm{C}$ residual mass continues to decrease at a very slow pace which can be associated with the densification of the char left. At the end of the survey conducted until $900{ }^{\circ} \mathrm{C}$, only about $8 \%$ of the original weight remained. After the sample was coated within the silica sol, more mass left the samples associated with the water and solvent residual from the coating process during the low-temperature weight loss step. During the main polymer degradation step, the degradation temperature is slightly increased, associated with the coating material slowing down the process. After the sample was heated up to maximum temperature, the remaining mass is increased to $\sim 23 \%$. Considering the mass uptake during the coating process was about $24 \%$, some of this residue was due to char left from cotton, and the rest was silica material. PVA-coated cotton fabric shows a low-temperature weight loss step similar to the cotton followed by the polymer degradation step. In the case of PVA coating, the degradation temperature slightly decreases. However, the residual mass percentage of the PVA coated sample is surprisingly $\sim 10 \%$, slightly higher than the cotton itself. Sample coated with PVA and silica shows almost exact thermal degradation pattern with the PVA coated sample.

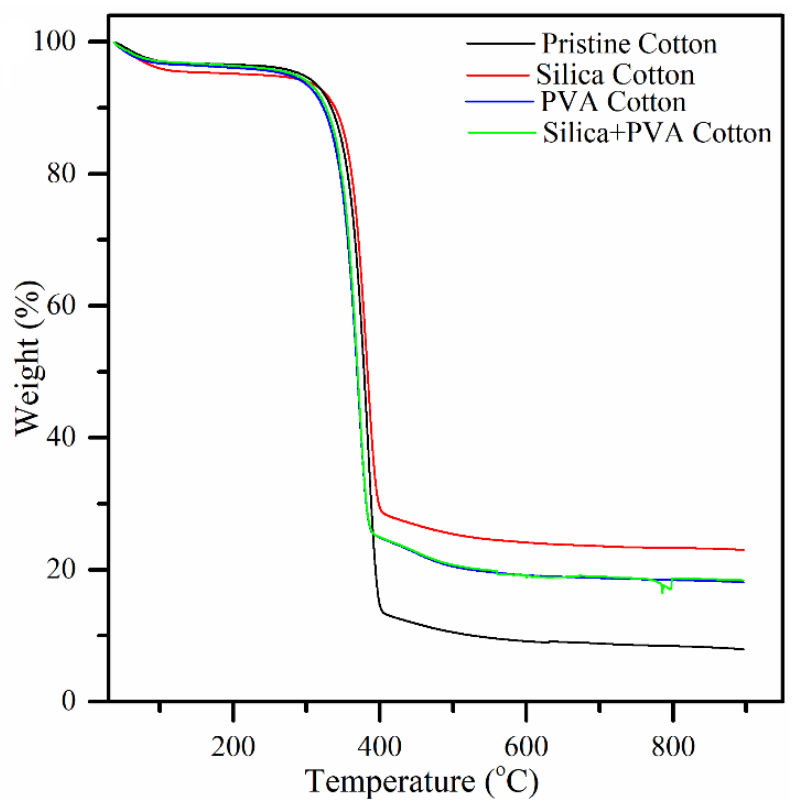

Figure 8: TGA weight loss of the pristine and coated cotton fabrics.
TGA thermograms of the pristine and coated PA 6.6 fabrics are given in Figure 9. The pristine sample has a low-temperature weight loss step associated with the removal of volatile species such as water. Since PA 6.6 is less hydrophilic than cotton, it is expected to have a lower moisture content, as the thermogram suggests. Furthermore, polymer degradation starts close to 400 ${ }^{\circ} \mathrm{C}$ and ends around $440{ }^{\circ} \mathrm{C}$ demonstrating that the degradation temperature of PA 6.6 is higher than cotton. After the sample heated to $900{ }^{\circ} \mathrm{C}, \sim 2 \%$ of the material is left. Compared to cotton, this amount is significantly low due to the aliphatic nature of PA 6.6. After the sample was coated with silica degradation pattern does not change. Nonetheless, the residual material of silica-coated PA 6.6 is $\sim 12 \%$, perhaps mainly consisting of silica material. When the sample was coated with PVA, thermal behavior and the residual amount are the same as the pristine fabric, indicating PVA does not affect the thermal behavior of PA 6.6, unlike the cotton samples. Once the sample is coated with silica and PVA, the degradation steps remain similar, whereas the residue amount is $\sim 8.5 \%$. Intermediate results indicate that the presence of silica has a significant effect on the thermal degradation of the samples.

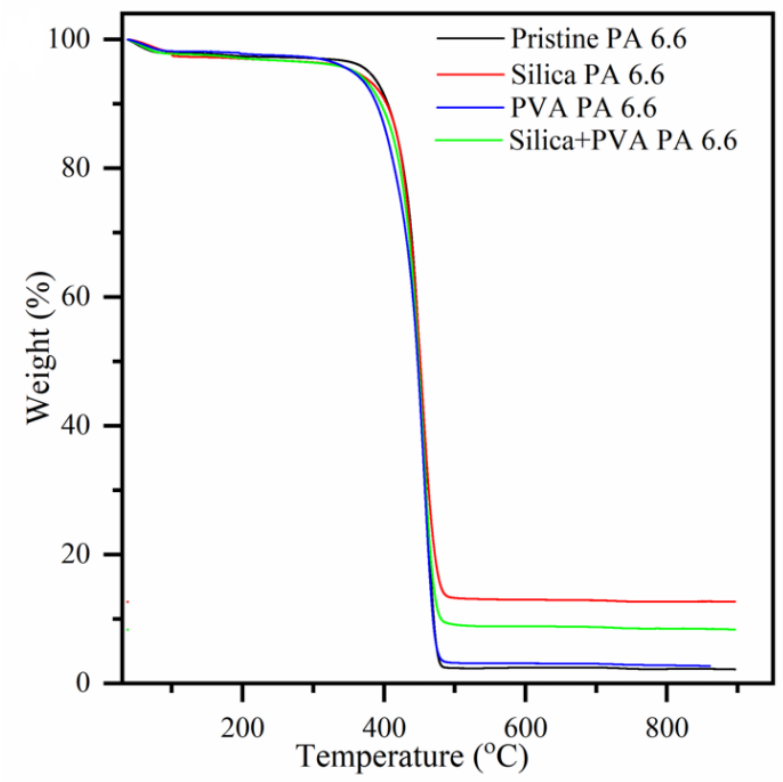

Figure 9: TGA weight loss of the pristine and coated PA 6.6 fabrics.

TGA results of the pristine and coated PET samples are given in Figure 10. As PET is a hydrophobic material, lowtemperature weight loss due to water desorption is not observed for PET samples. Polymer degradation starts just below $400{ }^{\circ} \mathrm{C}$ and ends at around $435{ }^{\circ} \mathrm{C}$. The residue amount left for the pristine PET fibers is about $17 \%$, attributed to the polymer's semi-aromatic structure. Upon silica coating onto the fibers, polymer degradation follows an almost exact polymer degradation pattern. At the end of the degradation, the residue amount is increased to $27 \%$, attributed to both silica remnants and the polymer char. When PET fibers were coated with PVA, the polymers' degradation starts below $400{ }^{\circ} \mathrm{C}$ then, following the PET degradation behavior. However, in the case of the PVA coated PET sample, the residue amount is decreased to $13.75 \%$, attributed to the presence of PVA on the fibers. PET fibers coated with silica and PVA show perhaps one of the most exciting results in this study. This sample degradation step is shifted about $5{ }^{\circ} \mathrm{C}$ to a higher temperature indicating the coating presence has a protective effect against degradation on the 
polymer. The residue amount for this sample is about $24 \%$ which is also very close to the sample coated with only silica.

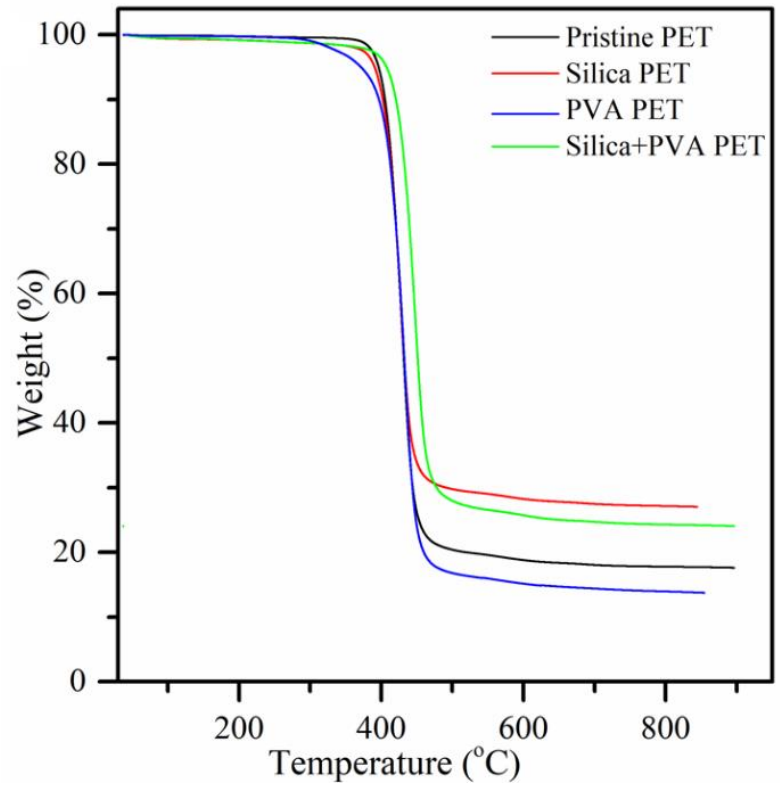

Figure 10: TGA weight loss of the pristine and coated PET fabrics.

Important parameters such as temperature at which $5 \%$ of the polymer are degraded $\left(\mathrm{T}_{\mathrm{d}} 5 \%\right)$, maximum degradation temperature $\left(\mathrm{T}_{\mathrm{d}} \max \right)$, and the residual amount at the end of each sample's thermogravimetric analysis are given Table 1. One of the pattern changes among the samples takes place for the $\mathrm{T}_{\mathrm{d}} 5 \%$ of the samples. The Td 5\% significantly decreases for all the substrates for the silica-coated sample, while pristine and other coating configurations show similar values. This behavior can be attributed to the introduction of more volatile species during the silica coating process. However, this argument contradicts silica+PVA coated samples since they still show similar $\mathrm{T}_{\mathrm{d}} 5 \%$ values to the pristine substrates. Another feasible discussion can be made based on the thermal properties of materials. The thermal conductivity of the silica materials is higher as they are compared to the polymers. Furthermore, specific heat capacities of the polymeric materials are expected to be higher than the silica material. We think the combination of such properties causes the whole material to absorb more energy, therefore, starting the degradation process at slightly lower temperatures. When samples are coated with silica and PVA, this behavior is not observed due to PVA presence. The Td max values in the table remain similar for each substrate type independent of the coating type, indicating that only polymer is degraded during these significant degradation steps. These results can be backed by the samples' residue amounts, which shows silica coating increases the residue amount significantly for all of the substrate types.

Table 1. The parameters recorded for the pristine and coated samples during TGA.

\begin{tabular}{|c|c|c|c|c|}
\hline Substrates & Coating & $\begin{array}{l}\mathbf{T}_{\mathrm{d}} \mathbf{5 \%} \\
\left({ }^{\circ} \mathrm{C}\right)\end{array}$ & $\begin{array}{l}\mathbf{T}_{d} \max \\
\left({ }^{\circ} \mathbf{C}\right)\end{array}$ & $\begin{array}{l}\text { Residual } \\
\text { Weight }\end{array}$ \\
\hline \multirow{4}{*}{ Cotton } & Pristine & 283 & 371 & 8.17 \\
\hline & Silica & 229 & 372 & 23.16 \\
\hline & PVA Coated & 275 & 370 & 18.29 \\
\hline & Silica+PVA & 285 & 371 & 18.57 \\
\hline \multirow{4}{*}{ PA 6.6} & Pristine & 365 & 445 & 2.26 \\
\hline & Silica & 345 & 441 & 12.74 \\
\hline & PVA & 340 & 443 & 2.71 \\
\hline & Silica+PVA & 345 & 444 & 8.48 \\
\hline \multirow{4}{*}{ PET } & Pristine & 393 & 426 & 17.71 \\
\hline & Silica & 392 & 430 & 27.03 \\
\hline & PVA & 363 & 425 & 13.75 \\
\hline & Silica+PVA & 392 & 432 & 24.15 \\
\hline
\end{tabular}

The mechanical tensile behaviors of the pristine and coated substrates were tested using a universal tensile test system, and the results are given in Figure 4. Pristine cotton fabric shows 28 $\mathrm{MPa}$ of strength and about $18 \%$ elongation at the breaking point, as given in Fig. 11. Tensile strength of the cotton sample coated in silica sol increased to $36 \mathrm{MPa}$ while elongation value decreases to $16 \%$. Sample coated with PVA shows $\sim 38 \mathrm{MPa}$ of tensile strength and $20 \%$ elongation. A coating on the sample 
increases the tensile strength of the material independent of coating being rigid (i.e., silica) or soft (i.e., PVA) material. This is attributed to the coating material filling the gaps in the fabric and connecting the fibers and yarns to each other, therefore increasing the tensile strength of the material. While this is happening, the elongation of the material is slightly decreased in the case of rigid coating (i.e., silica) and slightly increased in polymer coating (i.e., PVA), as expected. Perhaps the most exciting result among the cotton fabric samples was observed for the fabric coated with silica and PVA at the same time. This sample showed $\sim 26 \mathrm{MPa}$ of tensile strength, close to pristine cotton, while showing elongation of $51 \%$. This synergetic improvement in elongation is attributed to strong chemical adhesion between the substrate and coating material due to the silanization of both cotton and PVA. Cotton fabric made of staple fibers is enhanced in terms of the elongation via connection of the fibers PVA film, while this is chemically ensured with the silanol bridges created by the silica sol presence.

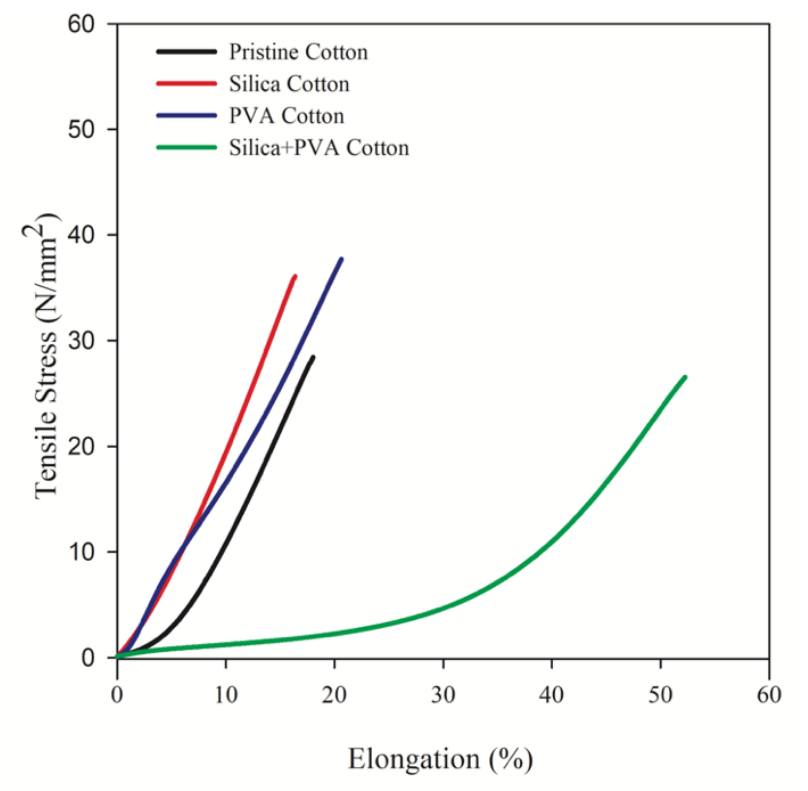

Figure 11: Mechanical tensile results of the pristine and coated cotton fabrics.

In Fig. 12, the mechanical tensile performance of the PA 6.6 samples is given. The pristine sample has a tensile strength of $\sim 71 \mathrm{MPa}$ and an elongation of $\sim 91 \%$. After the sample was coated within silica sol, the tensile strength of the fabric increased to $83 \mathrm{MPa}$ while the strain rate remains at 90\%. PA 6.6 samples coated with PVA exhibit $91 \mathrm{MPa}$ of strength and $106 \%$ of strain. Similar to the cotton fabrics, silica only or PVA only coatings increase the tensile strength of the fabric while silica coating slightly reduces the strain rate, and PVA coating increases the strain. Sample coated with silica and PVA has a tensile strength of $84 \mathrm{MPa}$ and $107 \%$ of strain. Looking at the performance of this sample, obviously, the strength of the materials is similar to the silica-coated sample, whereas the strain rate is similar to the PVA-coated sample. This behavior is different compared to the cotton samples. There are different possible explanations for this. The first one is the difference in the chemical structure of cotton and PA 6.6. Coating materials are expected to interact with the $-\mathrm{OH}$ on the surface of cotton fibers, whereas -NH groups are the expected groups of interaction on the PA 6.6 surfaces. Perhaps the interaction of the precursors is stronger for the PA 6.6 case. The second e-ISSN: 2148-2683 explanation can be based on the form of the fibers being staple fibers in the case of cotton and being filament fibers in PA 6.6. Filament fibers go from one end to the other end of the fabric coating material connect them along with the yarn axis, which results in better performance.

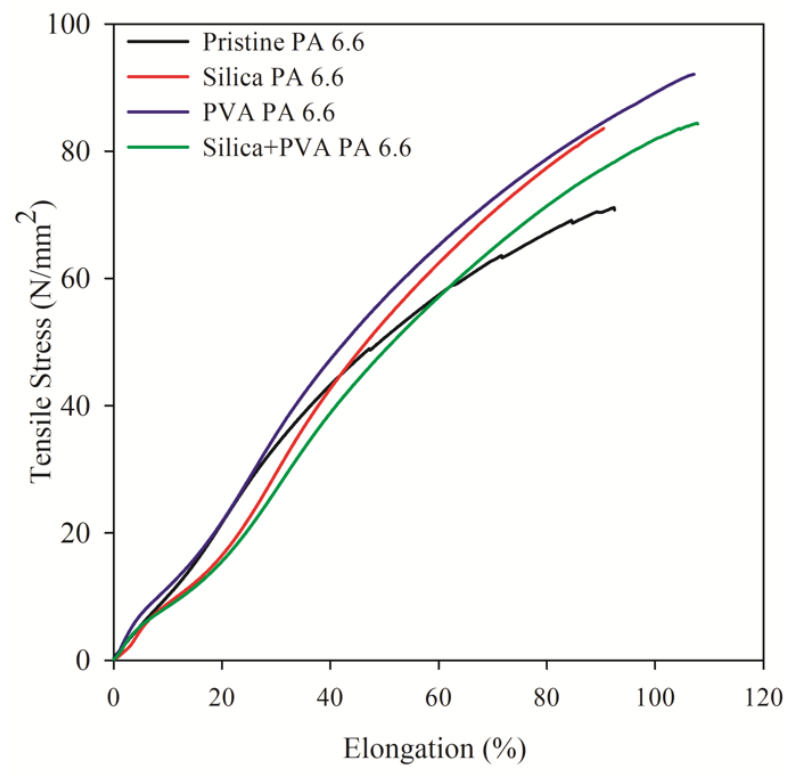

Figure 12: Mechanical tensile results of the pristine and coated PA 6.6 fabrics.

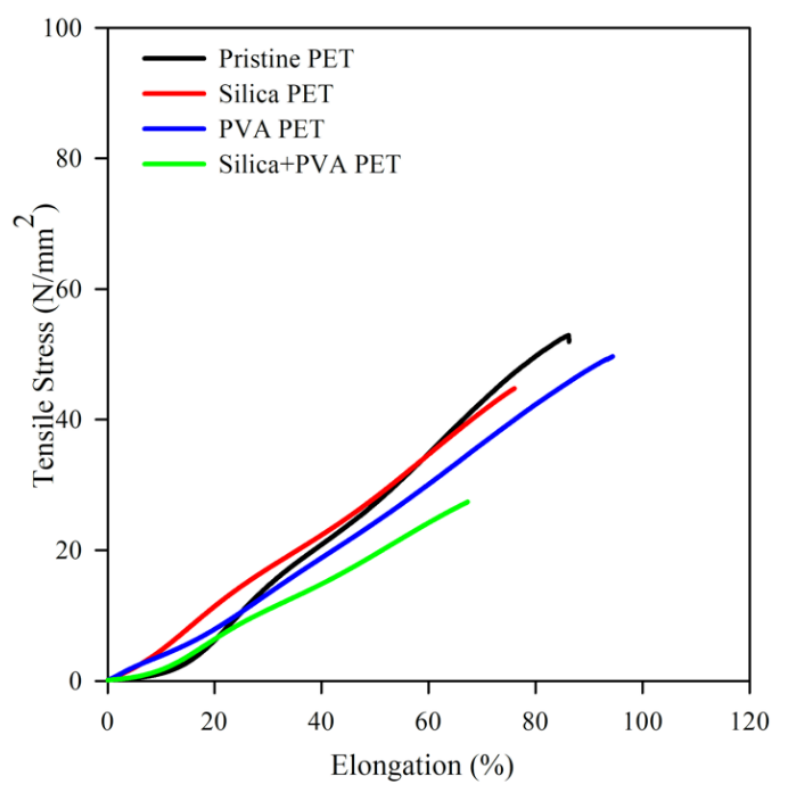

Figure 13: Mechanical tensile results of the pristine and coated PET fabrics.

In Fig. 13, the stress-strain behavior of the pristine and coated PET fabrics is given. Pristine PET fabric has a tensile strength of $\sim 53 \mathrm{MPa}$ and a strain rate of $\sim 86 \%$. After PET fabrics were coated within silica sol, tensile strength decreased to $\sim 45 \%$, and the strain rate is decreased to $76 \%$. PET sample coated with PVA showed a tensile strength of $50 \mathrm{MPa}$ and strain rate of $94 \%$. After the PET sample was coated with silica and PVA together, a drastic decrease in strength to $27 \mathrm{MPa}$ and strain to $67 \%$ observed. Compared to cotton and PA 6.6, PET samples showed very different responses attributed to the differences in the polymers' chemical structure. Both the cotton and PA 6.6 have functional groups to interact with the silica sol and PVA, 
whereas PET has only ester groups with very limited interaction. We think silica is a rigid material that might be damaging the fibers during the testing due to this lack of interaction. In this configuration, PVA cannot improve the interaction with PET fibers since it cannot interact with the substrate as well.

The results of the tensile testing are given in Table 2. As discussed above, the overall effect of the coating is highly dependent on the substrate type. This can be attributed to several factors such as the chemical characteristics of the polymer and the fabric structure (i.e., weaving pattern, the weight of the fabric, yarn type etc.). A comparison of the mechanical changes within the raw material groups according to the coating type is more reasonable in this case. However, there is a trend that can be deduced from the data. Polymer with functional groups that can chemically interact (i.e., cotton and PA 6.6) with the coating materials show similar performance changes with the coating type. Coating cotton and PA 6.6 with silica and PVA separately increase the tensile strength of the fabrics, whereas coating with PVA and silica together results in lower tensile strength compared to the separate coatings. Furthermore, PET also shows a reduction in the tensile strength when coated with PVA+silica.

Table 2. Tensile testing results of the pristine and coated fabrics.

\begin{tabular}{|c|c|c|c|c|c|}
\hline Substrate & Coating & $\begin{array}{c}\text { Tensile } \\
\text { Strength (MPa) }\end{array}$ & $\begin{array}{l}\text { Std. } \\
\text { Dev. }\end{array}$ & $\begin{array}{l}\text { Elongat } \\
\text { ion } \\
(\%)\end{array}$ & $\begin{array}{l}\text { Std. } \\
\text { Dev. }\end{array}$ \\
\hline \multirow{4}{*}{ Cotton } & Pristine & 28,0 & 0,2 & 18,2 & 0,4 \\
\hline & w/ Silica & 36,0 & 2,2 & 16,0 & 0,8 \\
\hline & w/ PVA & 37,8 & 2,4 & 20,2 & 1,0 \\
\hline & w/ Silica+PVA & 25,9 & 9,7 & 51,0 & 0,7 \\
\hline \multirow{4}{*}{ PA 6.6} & Pristine & 70,9 & 0,8 & 91,0 & 0,2 \\
\hline & w/ Silica & 83,3 & 0,8 & 90,2 & 2,3 \\
\hline & w/ PVA & 91,4 & 2,0 & 106,7 & 2,8 \\
\hline & w/ Silica+PVA & 84,0 & 3,9 & 107,2 & 3,1 \\
\hline \multirow{4}{*}{ PET } & Pristine & 52,8 & 1,9 & 85,9 & 2,1 \\
\hline & w/ Silica & 44,8 & 1,4 & 75,9 & 2,3 \\
\hline & w/ PVA & 50,0 & 9,3 & 94,5 & 2,6 \\
\hline & w/ Silica+PVA & 27,3 & 5,9 & 67,5 & 6,0 \\
\hline
\end{tabular}

\section{Conclusions and Recommendations}

The effect of silica, PVA, and silica+PVA coatings on cotton, PA 6.6, and PET fabric materials was comparatively studied. Morphological analysis of the samples in SEM showed material type, fiber, and fabric structure play an important role on the formation of the coating material. FTIR analysis of the samples showed that detection of the coating signals was difficult for two reasons. One reason is the signal overlap of the coating and materials. Another reason is the low thickness of the coatings causing hard-to-detect signals. Despite these reasons, FTIR spectra of the PA 6.6 samples have indications of the silica coating on the surface of the fabrics. The TGA analysis showed the effect of the coating materials on the degradation behavior of the fibers. Silicacoated materials showed higher residue amounts and lower
$\mathrm{T}_{\mathrm{d}} 5 \%$ values in general. This result was associated with the specific heat and thermal conductivity of the materials. The mechanical performance of the fibers was enhanced after the coating processes in general. The highest improvement was observed for the PA 6.6 substrates, attributed to the fibers' continuous structure and the nature of the chemical interactions between coating and substrate.

\section{Acknowledge}

We would like to thank The Scientific and Technological Research Council of Turkey (TUBITAK) (Project Number: 118C100). We also offer our gratitude to Turkish Aerospace Scientific Research Projects program (TUSAŞ BAP). 


\section{References}

Akyildiz, H. I., Lo, M., Dillon, E., Roberts, A. T., Everitt, H. O., \& Jur, J. S. (2014). Formation of novel photoluminescent hybrid materials by sequential vapor infiltration into polyethylene terephthalate fibers. Journal of Materials Research, 29(23), 2817-2826. https://doi.org/10.1557/jmr.2014.333

Akyildiz, H. I., Stano, K. L., Roberts, A. T., Everitt, H. O., \& Jur, J. S. (2016). Photoluminescence Mechanism and Photocatalytic Activity of Organic-Inorganic Hybrid Materials Formed by Sequential Vapor Infiltration. Langmuir, 32(17), 4289-4296. https://doi.org/10.1021/acs.langmuir.6b00285

Allen, A., Foulk, J., \& Gamble, G. (2007). Preliminary Fouriertransform infrared spectroscopy analysis of cotton trash. Journal of Cotton Science, 11(1), 68-74.

Amann, M., \& Minge, O. (2012). Biodegradability of poly(vinyl acetate) and related polymers. Advances in Polymer Science, 245(January 2012), 137-172. https://doi.org/10.1007/122011-153

Berendjchi, A., Khajavi, R., \& Yazdanshenas, M. E. (2013). Application of nanosols in textile industry. International Journal of Green Nanotechnology, 5(1), 1-7. https://doi.org/10.1177/1943089213506814

Boticas, I., Dias, D., Ferreira, D., Magalhães, P., Silva, R., \& Fangueiro, R. (2019). Superhydrophobic cotton fabrics based on $\mathrm{ZnO}$ nanoparticles functionalization. SN Applied Sciences, 1(11). https://doi.org/10.1007/s42452-019-1423-2

Chung, C., Lee, M., \& Choe, E. K. (2004). Characterization of cotton fabric scouring by FT-IR ATR spectroscopy. Carbohydrate Polymers, 58(4), 417-420. https://doi.org/10.1016/j.carbpol.2004.08.005

Costa, H. S., Mansur, A. A. P., Pereira, M. M., \& Mansur, H. S. (2012). Engineered hybrid scaffolds of poly(vinyl alcohol)/bioactive glass for potential bone engineering applications: Synthesis, characterization, cytocompatibility, and degradation. Journal of Nanomaterials, 2012. https://doi.org/10.1155/2012/718470

De Campos, B. M., Calefi, P. S., Ciuffi, K. J., De Faria, E. H., Rocha, L. A., Nassar, E. J., ... Maia, I. A. (2014). Coating of polyamide 12 by sol-gel methodology. Journal of Thermal Analysis and Calorimetry, 115(2), 1029-1035. https://doi.org/10.1007/s10973-013-3384-9

Ghasemi, H., Mirzadeh, A., Bates, P. J., \& Kamal, M. R. (2014). Effect of Polyamide 66 on the Mechanical and Thermal Properties of Post-Industrial Waste Polyamide 6. Polymer Plastics Technology and Engineering, 53(17), 1794-1803. https://doi.org/10.1080/03602559.2014.935398

Giustino, F. (2005). Infrared Properties Of The Si-Sio 2 Interface From First Principles.

Gurav, J. L., Jung, I. K., Park, H. H., Kang, E. S., \& Nadargi, D. Y. (2010). Silica aerogel: Synthesis and applications. Journal of Nanomaterials, 2010, 23. https://doi.org/10.1155/2010/409310

Islam, S. R., Yu, W., \& Naveed, T. (2019). Influence of silica aerogels on fabric structural feature for thermal isolation properties of weft-knitted spacer fabrics. Journal of Engineered Fibers and Fabrics, 14. https://doi.org/10.1177/1558925019866446

Ismail, W. N. W. (2016). Sol-gel technology for innovative fabric finishing-A Review. Journal of Sol-Gel Science and Technology, $78(3)$ 698-707. https://doi.org/10.1007/s10971-016-4027-y

Jelle, B. P., Baetens, R., \& Gustavsen, A. (2015). Aerogel insulation for building applications, in the sol-gel handbook. 1385-1412.

Kokabi, M., Sirousazar, M., \& Hassan, Z. M. (2007). PVA-clay nanocomposite hydrogels for wound dressing. European Polymer Journal, 43(3), 773-781. https://doi.org/10.1016/j.eurpolymj.2006.11.030

Lee, K. J., Choe, Y. J., Kim, Y. H., Lee, J. K., \& Hwang, H. J. (2018). Fabrication of silica aerogel composite blankets from an aqueous silica aerogel slurry. Ceramics International, $\quad 44(2), \quad 2204-2208$. https://doi.org/10.1016/j.ceramint.2017.10.176

Li, F., Xing, Y., \& Ding, X. (2008). Silica xerogel coating on the surface of natural and synthetic fabrics. Surface and Coatings Technology, 202(19), 4721-4727. https://doi.org/10.1016/j.surfcoat.2008.04.048

Li, L., \& Yang, G. (2009). Variable-temperature FTIR studies on thermal stability of hydrogen bonding in nylon 6/mesoporous silica nanocomposite. Polymer International, 58(5), 503-510. https://doi.org/10.1002/pi.2559

Mansur, H. S., Sadahira, C. M., Souza, A. N., \& Mansur, A. A. P. (2008). FTIR spectroscopy characterization of poly (vinyl alcohol) hydrogel with different hydrolysis degree and chemically crosslinked with glutaraldehyde. Materials Science and Engineering C, 28(4), 539-548. https://doi.org/10.1016/j.msec.2007.10.088

Nadi, A., Boukhriss, A., Bentis, A., Jabrane, E., \& Gmouh, S. (2018). Evolution in the surface modification of textiles: a review. Textile Progress, 50(2), 67-108. https://doi.org/10.1080/00405167.2018.1533659

Nampi, P. P., Kume, S., Hotta, Y., Watari, K., Itoh, M., Toda, H., \& Matsutani, A. (2011). The effect of polyvinyl alcohol as a binder and stearic acid as an internal lubricant in the formation, and subsequent sintering of spray-dried alumina. Ceramics International, 37(8), 3445-3450. https://doi.org/10.1016/j.ceramint.2011.05.149

Natarajan, S., \& Jeyakodi Moses, J. (2012). Surface modification of polyester fabric using polyvinyl alcohol in alkaline medium. Indian Journal of Fibre and Textile Research, 37(3), 287-291.

Periyasamy, A. P., Venkataraman, M., Kremenakova, D., Militky, J., \& Zhou, Y. (2020). Progress in sol-gel technology for the coatings of fabrics. Materials, 13(8). https://doi.org/10.3390/MA13081838

Pingan, H., Mengjun, J., Yanyan, Z., \& Ling, H. (2017). A silica/PVA adhesive hybrid material with high transparency, thermostability and mechanical strength. RSC Advances, 7(5), 2450-2459. https://doi.org/10.1039/C6RA25579E

Pirzada, T., Arvidson, S. A., Saquing, C. D., Shah, S. S., \& Khan, S. A. (2012). Hybrid silica-PVA nanofibers via sol-gel electrospinning. Langmuir, 28(13), 5834-5844. https://doi.org/10.1021/la300049j

Pisal, A. A., \& Rao, A. V. (2016). Comparative studies on the physical properties of TEOS, TMOS and Na2SiO3 based silica aerogels by ambient pressure drying method. Journal of Porous Materials, 23(6), 1547-1556. https://doi.org/10.1007/s10934-016-0215-y

Prevolnik, V., Zrim, P. K., \& Rijavec, T. (2014). Textile Technological Properties of Laminated Silica Aerogel Blanket. Contemporary Materials, 1(5), 117-123. https://doi.org/10.7251/cm.v1i5.1507

Purwar, R., Sharma, S., Sahoo, P., \& Srivastava, C. M. (2015). 
Flexible sericin/polyvinyl alcohol/clay blend films. Fibers and Polymers, 16(4), 761-768. https://doi.org/10.1007/s12221-015-0761-y

Roe, B., \& Zhang, X. (2009). Durable Hydrophobic Textile Fabric Finishing Using Silica Nanoparticles and Mixed Silanes. Textile Research Journal, 79(12), 1115-1122. https://doi.org/10.1177/0040517508100184

Rosace, G., Guido, E., Colleoni, C., \& Barigozzi, G. (2016). Influence of textile structure and silica based finishing on thermal insulation properties of cotton fabrics. International Journal of Polymer Science, 2016(March). https://doi.org/10.1155/2016/1726475

Rubio, F., Rubio, J., \& Oteo, J. L. (1998). A FT-IR study of the hydrolysis of Tetraethylorthoselicate (TEOS). Spectroscopy Letters, 31(1), 199-219. https://doi.org/10.1080/00387019808006772

Shahidi, S., \& Wiener, J. (2013). Eco-Friendly Textile Dyeing and Finishing. Eco-Friendly Textile Dyeing and Finishing, (January 2013). https://doi.org/10.5772/3436

Talebi, Z., Habibi, N., \& Zadhoush, A. (2018). Surface Modification of Basalt Fibers by Nanostructured Silica Aerogel. Fibers and Polymers, 19(9), 1843-1849. https://doi.org/10.1007/s12221-018-7710-5

Teli, M. D., \& Annaldewar, B. N. (2017). Superhydrophobic and ultraviolet protective nylon fabrics by modified nano silica coating. Journal of the Textile Institute, 108(3), 460-466. https://doi.org/10.1080/00405000.2016.1171028

Wu, G., Yang, Y., Lei, Y., Fu, D., Li, Y., Zhan, Y., ... Teng, M. (2020). Hydrophilic nano-SiO2/PVA-based coating with durable antifogging properties. Journal of Coatings Technology and Research, 17(5), 1145-1155. https://doi.org/10.1007/s11998-020-00338-Z

Wu, J. W., Huang, Y. Q., Li, H. B., Runt, J., \& Yeh, J. T. (2018). Properties of polyamide 6,10/poly(vinyl alcohol) blends and impact on oxygen barrier performance. Polymer International, $\quad 67(4), \quad$ 453-462. https://doi.org/10.1002/pi.5528

Xu, J., Jiang, S. X., Peng, L., Wang, Y., Shang, S., Miao, D., \& Guo, R. (2019). AgNps-PVA-coated woven cotton fabric: Preparation, water repellency, shielding properties and antibacterial activity. Journal of Industrial Textiles, 48(10), 1545-1565. https://doi.org/10.1177/1528083718764908

Xu, X., Li, B., Lu, H., Zhang, Z., \& Wang, H. (2007). The interface structure of nano-SiO 2 /PA66 composites and its influence on material's mechanical and thermal properties. Applied Surface Science, 254(5), 1456-1462. https://doi.org/10.1016/j.apsusc.2007.07.014

Zeng, C., Wang, H., Zhou, H., \& Lin, T. (2015). Self-cleaning, superhydrophobic cotton fabrics with excellent washing durability, solvent resistance and chemical stability prepared from an SU-8 derived surface coating. RSC Advances, 5(75), 61044-61050. https://doi.org/10.1039/c5ra08040a 